\section{O futebol de mulheres na revista Placar: da objetificação à redenção}

\author{
Daniel Felipe de Oliveira Leal \\ Giovana Borges Mesquita
}

\section{Resumo:}

Este artigo tem como objetivo analisar as mudanças ocorridas nos critérios de noticiabilidade adotados pela Placar para a produção de reportagens sobre o futebol de mulheres. Trata-se da mais antiga e tradicional revista esportiva em circulação no Brasil. Olhar para as mudanças na produção da notícia possibilita observar as transformações pelas quais o periódico atravessou, em uma única década, passando de um produto que flertava com o passado de objetificação da mulher, para dar voz à modalidade, e dedicar, pela primeira vez na história, uma edição especial exclusiva ao futebol de mulheres. Este artigo é um fragmento de uma pesquisa maior sobre a Placar, que inclui a análise dos critérios de noticiabilidade, desde a década de 1990 até 2019. Para este artigo, realizamos uma análise de conteúdo qualitativa e quantitativa de 84 edições do periódico, entre 2011 e 2019, anos que envolvem as três últimas Copas do Mundo Feminina. Além de analisar as revistas, nossa pesquisa também optou por entrevistas com jornalistas que passaram pela Placar, como Juca Kfouri e Ricardo Corrêa.

Palavras-chave: Noticiabilidade. Futebol de Mulheres. Revista Placar.

\section{Women's soccer in Placar magazine: from objectification to redemption}

\begin{abstract}
:
This article aims at analysing the changes in the news' criteria adopted by Placar magazine for the production of features on women's football. It is the oldest and most traditional sports magazine in circulation in Brazil. Looking at the changes in news production makes it possible to notice the transformations which the magazine went through in a single decade, shifting from a product that flirted with objectifying women, to giving voice to the modality, and dedicating, for the first time in history, a special edition exclusive to women's football. This article is a fragment of a larger research on Placar, which includes the analysis of news criteria, since the 1990s until 2019. For this article, we carried out qualitative and quantitative content analysis of 84 issues of the magazine, between 2011 and 2019, years that comprise the last three Women's World Cups. In addition to analyzing the magazines, our research also opted for interviews with journalists who passed through Placar, such as Juca Kfouri and Ricardo Corrêa.
\end{abstract}

Keywords: Noticiability. Women's Soccer. Placar Magazine.
Recebido em: 13.07 .20

Aprovado em: 05.02.21

Daniel Felipe

de Oliveira Leal

Doutorando em Comunicação pela Universidade Federal de Pernambuco e membro do ReNEme - Rede Nordestina de Estudos em Mídia e Esporte.

E-mail: danielleal87@ gmail.com.

\section{Giovana Borges} Mesquita

Professora adjunta do curso de Comunicação do CAA-UFPE e do Programa de Pós-graduação em Comunicação da Universidade Federal de Pernambuco (UFPE).

E-mail: giovanamesquita@yahoo.com.br. 
relação entre jornalismo e futebol de mulheres tem despertado cada vez mais a atenção de pesquisadores no Brasil, especialmente nas duas últimas décadas ${ }^{1}$ (GOELLNER, 2003; 2005; KNIJNIK e SOUZA, 2004; MOURÃO e MOREL, 2005; BARRETO JANUÁRIO, 2019; COSTA, 2006; 2017). O que se evidencia na maioria desses estudos é que a cobertura jornalística sobre a temática não contribuiu como poderia para o fortalecimento e o respeito às mulheres no futebol. "Ao contrário, diversos estudos mostram o quanto as representações midiáticas fizeram uso de estereótipos para a representação da mulher atuando nos gramados de futebol, perpetuando, dessa forma, preconceitos que dificultaram demasiadamente o desenvolvimento da modalidade" (COSTA, 2017, p. 495).

Refletindo a busca pela igualdade de gênero na política, economia e no mercado de trabalho, as mulheres foram reprimidas nos esportes, proibidas de praticar, dentre outras modalidades, o futebol, entre os anos de 1941 e 1979. O Decreto-Lei no 3.199 de abril de 1941, em pleno Estado Novo, ditadura do governo Getúlio Vargas, instituiu o Conselho Nacional de Desportos (CND) e afirmava, no artigo 54, que "às mulheres não se permitirá a prática de desportos incompatíveis com as condições de sua natureza, devendo, para este efeito, o Conselho Nacional de Desportos baixar as necessárias instruções às entidades desportivas".

Figueiredo $(2019$, p. 81$)$ recorda que a proibição feminina à prática desse esporte acontece na década de 1940, justamente no período em que começa a transmissão radiofônica das partidas pelo Brasil e, por conseguinte, o consumo midiático dos clubes de futebol como produtos. Oficialmente, foram 38 anos sem uma partida feminina no Brasil, com as mulheres relegadas à clandestinidade. A diferença entre a primeira Copa do Mundo masculina e a primeira feminina foi de 61 anos (sendo a de mulheres iniciada em 1991, enquanto a masculina data de 1930).

Sem a criação de uma cultura de cobertura contínua da mídia, o futebol de mulheres foi, estruturalmente, permeado por contornos de invisibilidade, silenciamento (GOELLNER, 2003; BARRETO JANUÁRIO; VELOSO, 2019; FIGUEIREDO, 2019) e, ao ganhar publicidade, permanentemente alvo de metáforas associadas às linguagens que se ancoraram em evidências do tipo: "fragilidade, estética, masculinização e resistência” (MOURÃO; MOREL, 2005, p. 75).

O futebol de mulheres, especificamente, sofreu, em diferentes momentos, fases e contextos sociais com uma imprensa que atuou de maneira desconexa na disseminação de informações que colocavam em xeque a saúde e até a fertilidade feminina, com discursos biologizantes e misóginos (GOELLNER, 2005). A Placar, mais tradicional e longínqua revista esportiva nacional em atividade, nasceu em 1970, ainda durante o processo de proibição das mulheres no futebol, e demorou a tocar no tema. Os primeiros registros passam a figurar a partir da década de 1980, quando o periódico inicia, ainda que com forte irregularidade, a cobertura noticiosa de mulheres futebolistas.

O objetivo deste artigo é analisar as mudanças ocorridas nos critérios de noticiabilidade adotados pela Placar para a produção de reportagens sobre o futebol de mulheres. Olhar para as mudanças na produção da notícia possibilita observar

${ }^{1} \mathrm{O}$ Instituto Internacional de Futebol, em 2005, no Congresso com o tema Mulher, futebol e Europa, afirmou que o futebol feminino tem se tornado uma área de estudos emergente e envolvente, em proporções globais. as transformações pelas quais a revista atravessou, em uma única década, passando de um produto que flertava com o passado de objetificação e sexualização da mulher, para dar voz à modalidade, e dedicar, pela primeira vez na história, uma edição especial exclusiva ao futebol de mulheres.

Este artigo é um fragmento de uma pesquisa maior sobre a revista, que inclui a análise dos critérios de noticiabilidade ao longo das oito Copas do Mundo de mulheres, entre 1991 e 2019. Para o estudo, realizamos uma análise de conteúdo qualitativa e quantitativa de 84 edições do periódico, entre 2011 e 2019, anos que 
envolvem apenas as três últimas Copas do Mundo Feminina. Além de analisar as revistas, nossa pesquisa também optou por entrevistas com jornalistas que passaram pela Placar, como Juca Kfouri e Ricardo Corrêa.

\section{A Placar e o futebol de mulheres}

Multicolorida, novidade para época, a revista Placar revolucionaria o noticiário esportivo nacional pelas reportagens de impacto, criatividade, longevidade e, por que não dizer, polêmicas. Nascia forte, fruto da Editora Abril, aquela que é apontada por Ribeiro (2007, p. 208) como "a maior e melhor revista esportiva do Brasil (...), destinada a leitores interessados em reportagens mais elaboradas, inteligentes, escritas por feras do jornalismo esportivo".

Historicamente, foi e continua sendo uma revista voltada para o público masculino. De acordo com dados da Editora Abril, publicados em junho de $2020^{2}$, 90\% da audiência da revista é composta por homens e os outros 10\%, mulheres. De acordo com a mesma fonte, a Placar tem circulação nacional e possui 2.537.000 leitores ativos em todas as plataformas, o que engloba a revista física, nosso objeto de pesquisa, mas também a sua versão digital. Atualmente, o periódico tem uma tiragem mensal de 11.179 exemplares, entre vendas avulsas (3.200) e assinaturas (7.979).

Salvini e Marchi Júnior (2016) observam, a partir da Placar, a cobertura da imprensa sobre o futebol de mulheres apontando basicamente três momentos temporais dessa relação: 1) o esforço para apresentar jogadoras em poses ou ações que lembrem a normatividade de gênero, na década de 1980;2) a dicotomia na veiculação de informações e imagens de mulheres atletas e de modelos que jogavam futebol - década de 1990; e 3) o anseio pela profissionalização feminina nesse esporte, entre 2000 e 2010.

É interessante perceber que com o passar dos anos, as matérias vinculando a necessidade de demonstrações de beleza ou cuidados com a aparência, ao futebol, vão dando espaço para matérias que abordam questões relacionadas à falta de patrocínios ou mesmo o desempenho individual de Marta $^{3}$ (SALVINI; MARCHI JÚNIOR, 2016, p. 110).

$\mathrm{Na}$ década 2010, porém, observamos uma transitoriedade dessas noticiabilidades provocadas por uma gama de fatores conjuntos. Como apontado por Januário e Veloso (2019), vem sendo percebido no Brasil, desde 2015, o que se pode chamar de uma "primavera feminista", no que tange a temas relacionados ao empoderamento feminino e formas de representação da mulher na mídia, mais preocupada com uma retratação mais fidedigna à mulher contemporânea e suas conquistas. Outro marco relevante veio em 2019, com a oitava edição da Copa do Mundo, pela primeira vez transmitida pela TV Globo, líder em audiência no país. A transmissão trouxe recordes de audiência nacional e internacional (BARRETO JANUÁRIO; LIMA; LEAL, 2020).

Apontaremos adiante que, entre 2011 e 2019, o futebol de mulheres observa o surgimento de uma nova tendência nas noticiabilidades, com maior inclinação às notícias sobre questões técnicas em detrimento as de cunho sexuais e pejorativos. Assistimos, então, o nascimento e transitoriedade de novos valores-notícia (SILVA, 2014) no período que engloba três as Copas do Mundo analisadas.

\section{Noticiabilidade, organismo mutável: uma breve reflexão}

Uma das características do sistema de mídia é a sua particular predisposição para se adaptar a novos cenários, ambientes, valores e contextos históricos. Ou seja, ele é mutável. Alsina (2009, p. 55) defende a comunicação como "um ecossistema em permanente estado de mudança". Desde o século passado, uma infinidade de pesquisadores tem se debruçado a investigar os critérios que os jornalistas

${ }^{2}$ PubliAbril. Disponível em: http://publiabril.abril.com. br/marcas/placar/plataformas/revista-impressa. Acesso em 2 de jun. de 2020.

${ }^{3} \mathrm{~A}$ jogadora alagoana Marta possui seis prêmios de melhor do mundo da FIFA. Com 17 gols em Copas do Mundo, ela é a maior artilheira da história dos Mundiais entre homens e mulheres. 
utilizam para selecionar e identificar se uma situação é, de fato, noticiável (WOLF, 2003; TRAQUINA, 2005; SILVA, 2014). Como apresentaremos a seguir, os valores-notícia seguem o universo midiático, ou seja, não são rígidos nem estáticos.

Traquina (2005, p. 63) define o conceito de noticiabilidade como o "conjunto de critérios e operações que fornecem a aptidão de merecer um tratamento jornalístico, isto é, possuir valor como notícia". Além disso, o autor apresenta os critérios de noticiabilidade como um conjunto de valores-notícia que determinam se um acontecimento, ou assunto, é suscetível de se tornar notícia.

Refletindo sobre o processo de mutação da notícia, Jorge (2013, p. 11) compara as alterações nos contornos das news como a trajetória de um organismo vivo em contínuo processo de mudanças para se adaptar à sociedade. A notícia "é, assim, ao mesmo tempo, mutável (oscilante, sujeita a mutações) e mutante (sempre em mudança)".

Ou seja, novos critérios de noticiabilidade estão e continuarão surgindo dentro do organismo vivo da sociedade. De acordo com Gislene Silva $(2014$, p. 52), "é no percurso dessa longa cadeia produtiva da notícia que devemos investigar a rede de critérios de noticiabilidade". Como exemplo, trazemos a proposta da própria autora, que a partir dos levantamentos feitos por Traquina, Wolf e Kinczik e textos de autores brasileiros como Chaparro, Erbolato e Lage, propõe 12 valores-notícia para operacionalizar análises de acontecimentos noticiados ou eventos noticiáveis: impacto, proeminência, conflito, tragédia/drama, proximidade, raridade, surpresa, governo, polêmica, justiça, entretenimento/curiosidade e conhecimento/cultura.

Márcia Veiga da Silva (2018), por sua vez, acrescenta, a partir de um olhar mais contemporâneo sobre as rotinas produtivas, que a construção das notícias está atravessada por valores sociais e pela subjetividade dos jornalistas. A autora destaca também a existência de uma hierarquia de valores-notícia de gênero e sexualidade, assentada em uma racionalidade machista e misógina, que atravessa a produção de notícias e contribui para a reprodução, manutenção, ressignificação ou transformação de padrões de desigualdade no jornalismo (VEIGA DA SILVA, 2014). O reflexo dessa perspectiva andriarcal esteve presente por várias fases da Placar.

Por fim, destacamos a contribuição de Mesquita (2014) na discussão sobre as noticiabilidades. A pesquisadora observa a inclusão do agente externo às redações, ou seja, a audiência, como fator fundamental para a noticiabilidade de um determinado fato. Não em vão, nas redes sociais, por exemplo, muitos jornalistas passaram a observar os Trend Topics ${ }^{4}$ do Twitter para se balizar nos assuntos mais recorrentes do dia - ou mesmo passaram a se valer de ferramentas como o WhatsApp para receber sugestões de pautas e outras contribuições provenientes do público, classificado por Mesquita (2014) como audiência potente -, agente externo às redações, que passa a ter interferências na decisão dos jornalistas sobre algumas escolhas do que será noticiado.

\section{O futebol de mulheres sob a ótica da Placar}

Para entender como a revista Placar noticiou o futebol de mulheres na última década, analisamos publicações entre os anos de 2011 e 2019, período que envolve as três últimas Copas do Mundo Feminina e pelo qual a revista passou por três modificações administrativas e, consequentemente, de perfis editoriais.

Utilizamos como metodologia a Análise de Conteúdo (BARDIN, 1977), a qualitativa e a quantitativa, dessas publicações, a fim de identificar quais valores-notícia estão presentes ao longo do período. Além do levantamento bibliográfico,

${ }^{4}$ Traduzido como "tópico em tendência”, mas usado na versão em português como "Assuntos do Momento"; criado em 2010 pela rede social Twitter. nossa pesquisa também optou por entrevistas com editores da revista. A técnica da entrevista auxilia, dentre outros pontos, para que se evite buscar e valorizar apenas informações que confirmem nossos pressupostos (DUARTE, 2010).

Dentro do nosso espaço temporal previamente delimitado, observamos 1.429 notícias em 84 edições distintas. A concretização de que 23 dessas 84 edições 
(27,38\%) contêm notas, matérias ou reportagens sobre o futebol de mulheres (ou seja, pouco mais de uma menção a cada quatro edições), poderia nos induzir a concluir que o tão amplamente discutido silenciamento ao tema seria uma falácia. Mas, definitivamente, não é.

Dois pontos são cruciais nesta questão. Primeiro, observaremos na tabela a seguir que quase metade das veiculações $(43,5 \%)$ sobre o futebol de mulheres são frutos da categoria que destacamos como "Outros" - títulos que englobam publicações tais como: fotos-legendas, notas ou menções sobre o futebol de mulheres em colunas ou entrevistas. Em geral, são registros diminutos em um universo comumente superior às 100 páginas de um periódico mensal.

O segundo ponto para justificar e endossar o silenciamento é ainda mais simples e impactante: dos 1.429 conteúdos analisados em nove anos de Placar, apenas $46(3,22 \%)$ dizem respeito ao futebol praticado por mulheres. Significa que menos de quatro a cada 100 notícias publicadas eram sobre o tema. O que não quer dizer que não exista um progresso em curso. Tanto o quantitativo como o qualitativo das notícias vêm passando por transformações.

De acordo com Bardin (1977), uma boa categorização, como forma de impor organização às mensagens, deve possuir, dentre outras características, a exclusão mútua: quando um elemento incluído na categoria $\mathrm{X}$ não pode ser incluído na categoria Z. Seguimos à risca a instrução. Como exemplo, podemos citar a análise de texto por meio da conotação da mensagem (FONSECA JÚNIOR, 2006). Em determinadas publicações havia uma mescla de informações técnicas, mas que traziam jogo de palavras com conotações pejorativas. Optamos sempre pelo elemento predominante para chegarmos à tabela abaixo.

Tabela 1 - O perfil das publicações da Placar sobre o futebol de mulheres

\begin{tabular}{|c|c|c|c|c|c|c|}
\hline \multicolumn{7}{|c|}{ Década analisada: 2011-2019 } \\
\hline \multirow[b]{2}{*}{ Gênero } & Entrevista & Matéria & Reportagem & Outros & \multicolumn{2}{|c|}{ Inserções totais } \\
\hline & $1(2,2 \%)$ & $22(47,8 \%)$ & $3(6,5 \%)$ & $\begin{array}{c}20 \\
(43,5 \%)\end{array}$ & \multicolumn{2}{|c|}{46} \\
\hline \multirow{3}{*}{$\begin{array}{l}\text { Presença de } \\
\text { Ilustrações }\end{array}$} & $\begin{array}{c}\text { Não: } 12 \\
(26,09 \%)\end{array}$ & & & & & \\
\hline & Sim: 34 & $\begin{array}{c}\text { Fotogra- } \\
\text { fia }\end{array}$ & \multicolumn{2}{|c|}{ Gráfico } & $\begin{array}{c}\text { Dese- } \\
\text { nho }\end{array}$ & $\begin{array}{l}\text { Info- } \\
\text { gráfico }\end{array}$ \\
\hline & $(73,91 \%)$ & $\begin{array}{c}34 \\
(100 \%)\end{array}$ & \multicolumn{2}{|l|}{0} & 0 & $\begin{array}{c}5 \\
(14,7 \%)\end{array}$ \\
\hline \multirow{2}{*}{$\begin{array}{c}\text { Conotação das } \\
\text { publicações }\end{array}$} & Sexual & Técnica & \multicolumn{2}{|c|}{ Pejorativa } & \multicolumn{2}{|c|}{ Neutra } \\
\hline & $\begin{array}{c}5 \\
(10,87 \%)\end{array}$ & $\begin{array}{c}29 \\
(63,04 \%)\end{array}$ & \multicolumn{2}{|c|}{$\begin{array}{c}1 \\
(2,17 \%)\end{array}$} & \multicolumn{2}{|c|}{$\begin{array}{c}11 \\
(23,92 \%)\end{array}$} \\
\hline
\end{tabular}

Embora o quantitativo das notícias sobre mulheres futebolistas ainda seja inferior a $4 \%$ do total das publicações no período, a qualidade do noticiário em torno do futebol feminino passa por uma metamorfose. Os anos de 2010 marcam uma revolução no futebol de mulheres no Brasil e no mundo. Maior número de publicações na Placar, maior número de notícias condizentes à questão técnica das atletas e da modalidade e audiência recorde na Copa do Mundo 2019.

Apesar de não fazer parte do nosso corpus de análise, faz-se necessário recorrer a anos anteriores para fazer um comparativo à década em análise e embasar nossas conclusões. Na década de 1990, das 32 publicações sobre o futebol de mulheres, 19 (59,38\%) tinham predominantemente uma conotação sexual; a abordagem "Técnica" foi predominante em nove notícias (28,13\%). Na década de 2000, as 
inserções totais sobre o assunto caíram de 32 para 26, mas, por outro lado, o tipo de abordagem das notícias com conotações sexuais teve uma queda abrupta para $3,84 \%$ - ou seja, uma notícia no universo de 26 ; a abordagem do futebol de mulheres passou a ser "Técnica" em 20 publicações $(76,93 \%)$ - em números brutos, mais do que o dobro das nove notícias com mesmo formato da década anterior.

Por fim, entre 2011 e 2019, observamos um acentuado aumento no número de conteúdos envolvendo o futebol praticado por mulheres: de 26, nos dez anos anteriores, para 46 . Um retrocesso, porém, é observado nas conotações das notícias sexuais, que voltaram a subir: desta vez ficando em 10,87\% (cinco de 46). O número de notícias “Técnicas” percentualmente caiu de 76,93\% para 63,04\%. Em contrapartida, em números brutos, novamente, houve um aumento desse tipo de informação: de nove na década de 1990, para 20 na década de 2010 e, agora, para 29 - aumento superior a 200\% em relação ao decenário de 1990.

Analisamos os anos, entre 2011 e 2019, em três blocos distintos. Até mesmo porque a Placar tem três fases distintas no período, entre 2011 e 2015; 2015 e 2016; e 2016 até o final de 2019. Por que dividimos a década de 2010 em três momentos? Entre 2011 e 2015, a Placar viveu mais uma, dentre outras tantas, severas crises financeiras5. Em 2014, a Editora Abril vendeu dez revistas para a Editora Caras. A revista esportiva teria o mesmo destino em junho do ano seguinte, retornando à antiga casa somente dois anos depois.

\section{Um flerte com o passado}

Os primeiros anos da década 2010 soam como uma entrada no túnel do tempo rumo ao retrocesso no tangente ao futebol de mulheres. Com trocadilhos machistas e temáticas que em nada remetiam a entrada em uma década que terminaria promissora, Placar flerta por diversas vezes com o passado. A primeira matéria sobre futebol de mulheres, na década, vem em junho de 2011, na seção "Aquecimento", com um texto construído em estruturas associadas a masculinidade e ao machismo. Primeiramente, pelo título: "Meninas sem salto alto", que remete ao calçado comum às mulheres.

Em seguida, o texto começa da seguinte forma:

Ele entende a cabeça das mulheres, sabe como conquistar a confiança delas e fazer com que sejam fiéis a suas instruções. Não, não se trata de um Dom Juan moderno. Ele é Kleiton Lima, técnico da seleção feminina de futebol, o homem com a missão de comandar o Brasil rumo a seu primeiro título de expressão. (PLACAR, 2011a, p. 30).

O texto enfatiza que é um homem que tem a missão de levar as mulheres ao título. O técnico, dominador (BOURDIEU, 2012), que sabe "conquistar a confiança" e "entende a cabeça das mulheres".

Em julho de 2011, a revista traz mais uma notícia envolvendo mulheres futebolistas e novamente estigmatizando o esporte como um objeto sexualizado. Com o título "Pelada na várzea alemã" e subtítulo "Anfitriã do mundial, seleção da Alemanha tira a camisa (e todo o resto) e nem leva amarelo", o texto afirma que "como boas anfitriãs, as alemãs trataram de mostrar um pouco mais do que bola no pé" (PLACAR, 2011b, p. 84).

$\mathrm{Na}$ edição 1357, a revista traz uma foto-legenda para informar, em tom ab-

${ }^{5}$ Em 1990, ano da mais severa crise financeira da Placar, a revista chegou a encerrar as atividades por três meses encerrando uma sequência de 20 anos de publicações

semanais ininterruptas. solutamente jocoso, o desfecho negativo da Seleção Brasileira no mundial da Alemanha. Não traz em que etapa do torneio as mulheres foram eliminadas, como se deu a eliminação, o placar dos jogos, os públicos, a classificação final, nada disso. A notícia, em foto-legenda, da eliminação prezou pelos trocadilhos e a busca pela desqualificação das atletas.

Ressuscitando a tradição das "musas", da década de 1990, a Placar noticiou, em novembro de 2012, na edição 1371, uma matéria intitulada "Pelada pela musa", 
onde apresentava um conjunto de modelos dispostas a serem musas do XV de Piracicaba-SP. A publicação, na verdade, em nada tem a ver com o futebol, à exceção ao fato de as modelos posarem, de salto alto (literalmente), para fotografia com a camisa do clube do interior paulista simulando uma partida fictícia.

Em abril de 2013, a Placar anuncia um novo projeto editorial, estabelecido sob cinco pilares: profundidade, rigor estatístico, excelência visual, arquivo histórico e bom humor. O projeto durou pouco mais de dois anos, até julho de 2015, encerrando-se com a venda da revista à Editora Caras, que realiza uma profunda mudança no quadro de jornalistas e de perfil editorial. A revista promete ir além do futebol masculino em suas páginas. Edgardo Martolio foi o diretor-superintendente da Placar e o responsável por comandar a equipe.

\section{Placar na Caras: "Esquizofrênica"}

A tradicional publicação esportiva, que na década de 1980 chegou a ter 50 colaboradores na equipe, passou a ter Celso Unzelte, como editor-chefe, e Rodolfo Rodrigues, como editor, além de dois estagiários. Unzelte (2019), convidado para assumir a equipe, ficou apenas três meses no cargo. Por desentendimentos sobre a linha editorial da revista com Martolio, pediu demissão apenas três meses na função que exercia.

De fato, o período é bastante confuso, com tabelões gigantes, muitos resultados de diversos esportes e, a cada edição, dezenas de notas, que vinham na seção "Resumão", no qual cada dia do mês era destacado por algum evento esportivo. Em pouco mais de um ano da Placar na Caras, registramos sete notas sobre o futebol de mulheres, com conotação técnica, em formato de lead clássico. Outra observação de Unzelte (2019), também facilmente detectável, foi relativa à busca indiscriminada da revista por patrocínios. Conforme o jornalista apontou, de fato, existe, na edição 1408, de novembro de 2015, uma longa entrevista assinada por Edgardo Martolio com o então ministro dos Esportes, George Hilton. Na entrevista, porém, não existe confrontação a problemas como investimento em infraestrutura no esporte, dentre outras questões importantes na época.

Outra entrevista com perfil "chapa-branca", nesta mesma edição 1408, vem em uma matéria sobre o pouco expressivo Jogos Mundiais Militares. A Seleção Feminina, inclusive, ganha destaque com o vice-mundial. Na matéria, um histórico do esporte militar no Brasil, com aspas de informações repassadas pela assessoria do Ministério da Defesa.

Uma virtude do período da Placar na Caras, há de se ressaltar, foi a ausência de qualquer vestígio de objetificação da mulher. Embora não tenhamos nos aprofundado neste campo da pesquisa, é perceptível o aumento de publicações alheias ao futebol masculino. Especificamente sobre o futebol de mulheres, além das notas nos "Resumões", a fase também tem duas reportagens relevantes. A edição 1409, de dezembro de 2015, trouxe seis páginas destacando a Ferroviária, campeã da Copa Libertadores feminina. O Santos (em 2009 e 2010) e o São José (em 2011, 2013 e 2014) já haviam conquistado o título anteriormente, porém sem qualquer destaque da revista.

Foi ainda no período de Caras que a Placar trouxe mais uma capa histórica para o futebol de mulheres. Pela terceira vez em 46 anos a revista trouxe uma jogadora no seu espaço mais nobre. E, pela primeira vez, Marta ocupa a primeira página. Ao lado de Neymar, a já eleita cinco vezes melhor atleta de futebol do mundo, enfim tem vez no front page do periódico. Ambos são protagonistas da edição 1418, de agosto de 2016, na chamada sobre as Olimpíadas daquele ano, no Rio de Janeiro. Apesar da manchete, Marta não recebe grande destaque dentro da edição. Citada como "Pelé de saia", aparece como linha de frente da equipe que tentaria o ouro de maneira inédita - o que acabou não acontecendo. Encerrava-se ali a conturbada,

${ }^{6}$ Esta expressão quer dizer que o jornalista, ou o veículo ao qual pertence, é patrocinado/manipulado pelo governo. 
porém com alguns frutos positivos ao futebol de mulheres, a etapa da Placar na Editora Caras.

\section{Mais do que o perdão, a redenção}

Após 15 edições sob a tutela da Editora Caras, a Placar retorna para a antiga casa em 2016, a Editora Abril, que consegue negociar dívidas e a volta da revista. Em processo de recuperação judicial e com poucos recursos, a Abril não tem sequer uma equipe para dar andamento à revista esportiva. É quando volta à cena o jornalista Ricardo Corrêa, por décadas editor de fotografia da Placar, convidado para assumir as diretrizes do periódico. Corrêa aceita o desafio, mas com uma condição: a revista seria feita por sua equipe, de maneira terceirizada, no seu estúdio privado em São Paulo. Com um grupo de mais dois editores, um de texto e outro de fotografia, além de colaboradores pontuais, Placar tem vida e perfil editorial novos.

A revista, então, passou a funcionar com um planejamento de pautas anuais, prevendo os grandes eventos agendados para os determinados meses. Um dos grandes trunfos para ter edições mais trabalhadas é o arquivo histórico da revista. De acordo com Corrêa (2019), o acervo da Placar tem cerca de 6 milhões de imagens coloridas, desde a década de 1970.

No perfil de ser um documento não perecível, com temas históricos, a revista se deu conta de que o futebol de mulheres, passados mais de 35 anos desde o fim da proibição por lei, também já tinha uma longa trajetória. E assim tratou de dar-lhe espaços antes pouco ocupados, com temas voltados à modalidade, a destaques técnicos e a premiações no mundo da bola, o que aconteceu "por conta da própria evolução do futebol feminino" (CORRÊA, 2019, informação verbal).

O primeiro exemplo desse tratamento que buscava retratar a "naturalidade" do futebol de mulheres veio na edição 1444, de outubro de 2018. Pela segunda vez, Marta apareceu dividindo a capa da Placar com um jogador, desta vez o croata Modric. Ambos ganharam destaque por terem sido eleitos os melhores jogadores de futebol do mundo. No caso da brasileira, eleita pela sexta vez.

Apesar da proporcionalidade das imagens na chamada na capa, o mesmo não pôde ser visto dentro da revista. Das 68 páginas da edição, apenas duas foram destacadas para o futebol de mulheres. Uma com uma foto de Marta e outra com texto. No título, exaltação: "É hexa! É genial, É Marta!", seguindo com o subtítulo "Superando preconceitos e a extinção de alguns de seus clubes, Marta se manteve no topo por mais de uma década e se eternizou como a maior vencedora do prêmio da Fifa".

Sobre esta publicação, Corrêa (2019) explicou que a proporcionalidade do espaço para o futebol de homens e de mulheres, na visão dele, corresponde ao interesse do público pelas modalidades, deixando em aberto a possibilidade de se aumentar o espaço no futuro.

A desproporcionalidade no número de informações entre o futebol de homens e mulheres foi mantida na revista de julho de 2019. Esta, porém, não foi uma edição qualquer. Trata-se, pelo editorial publicado, do passo mais emblemático do revisionismo histórico da Placar relativo ao futebol de mulheres. A edição 1453 trouxe sob o título "A busca pela igualdade" um pedido de desculpas histórico pela trajetória machista da revista ao noticiar, não só o futebol de mulheres, mas as mulheres no esporte como um todo.

Placar é uma revista de futebol, não há dúvida. Mas ajustes são necessários. Um deles é o espaço que a mulher ocupa em nossas páginas. Nas décadas de 1980 e 1990, olhávamos o futebol feminino com uma visão equivocada, quase objetificando as mulheres jogadoras. Pedimos perdão por aquele período de ignorância e buscamos evoluir. Hoje não somos uma revista do dia a dia, realizamos edições especiais - e esta que chega a suas mãos é uma delas (PLACAR, 2019, ed. 1453, p.4 grifo nosso). 
De acordo com Ricardo Corrêa (2019), a ideia de trazer o pedido surgiu a partir de uma notícia que ele leu no portal UOL. A notícia, publicada pelo Blog Dibradoras, trazia a manchete: "O futebol feminino já foi visto assim - o que diriam dessas imagens hoje?". A foto principal era a capa da edição 1106, de agosto de 1995, em que modelos aparecem de costas, com uniformes provocativos, sensuais, remetendo aos da Seleção Brasileira.

O pedido de desculpas veio numa edição em que a manchete trazia "Os melhores do século 21", com uma lista dos 100 melhores jogadores e das 20 melhores jogadoras de futebol do período. Na capa, pela terceira vez, Marta despontava como representante feminina, desta vez ao lado da norte-americana Abby Wambach. Elas, todavia, eram minoria absoluta: dos 16 retratos na capa da revista, apenas dois eram de mulheres - 14 de jogadores homens. Das 68 páginas da referida edição 1453, sete ficaram para o ranking das mulheres.

Os textos da reportagem seguiram uma tendência desta nova fase da Placar, que buscava especialistas para parcerias pontuais. No caso, cinco jornalistas do site Planeta do Futebol Feminino assinaram os textos. Menos o principal, de abertura, que traz uma nova reflexão da revista, como uma continuidade do editorial, sobre o futebol de mulheres. Placar, então, admite sua incapacidade de momento para escrever sobre o tema e anuncia a parceria.

O sucesso da Copa do Mundo, com audiências recordes nas televisões do Brasil e do mundo (BARRETO JANUÁRIO; LIMA; LEAL, 2020) aguçou ainda mais o progressivo interesse da Placar pelo futebol de mulheres. A ponto de, em novembro de 2019, pela primeira vez na história, a revista voltar a provocar uma nova modalidade de distinção de gênero, mas desta vez excluindo os homens: uma tiragem inteira era dedicada às futebolistas. Na capa, enfim sozinha, Marta. Sob a manchete "Dossiê futebol feminino", a revista anunciava: "a edição especial traz raio-X da modalidade no Brasil e no mundo".

A edição 1457, mais uma vez histórica, trouxe dez matérias. Todo o conteúdo foi construído, outra vez, a partir de parcerias com sites especializados no assunto. Além do Planeta do Futebol Feminino, participaram da edição \#Jogamiga, Elas no Ataque e o Jogadelas. Apontamos o primeiro destaque para o editorial, novamente com reflexões sobre a relação passada da Placar com o futebol de mulheres, mas, desta vez, com um adendo: a aprovação e o reforço do pedido de desculpas, realizado três edições antes, do mais icônico diretor de redação da revista, Juca Kfouri (2019a).

O reconhecimento do erro é ótimo exemplo para inúmeros veículos brasileiros que costumam manter silêncio sobre seus equívocos editoriais. Desnecessário lembrar a responsabilidade deste blogueiro no período mencionado, razão pela qual assino embaixo o texto da revista, apenas com a retirada do "quase" antes do "objetificando". Os tempos muram, felizmente (KFOURI, 2019b, grifo nosso).

A sugestão de Juca Kfouri para que o "quase" fosse retirado da frase em questão foi atendido por Ricardo Corrêa no editoral assinado por ele na edição 1457. Esta publicação traz espaços antes jamais vistos para a modalidade, temas inéditos (para nós, o nascimento de novos valores-notícia) tais quais manifestação, ativismo e militância; reconhecimento e exaltação; além de outros nem tão debutantes assim, como a trajetória histórica do futebol de mulheres, o tabu de que "mulher não sabe jogar bola" e o reconhecimento à Marta. Conforme disse Ricardo Corrêa (2019) ao traçar o perfil editorial da Placar nesta fase, a busca passou a ser transformar a revista em um documento histórico, atemporal, com estatísticas e histórias.

Certamente nenhuma atleta na competição teve mais visibilidade midiática do que Megan Rapinoe, atacante dos Estados Unidos e militante da causa LGBTI+, que se tornou uma voz ativa pelo futebol de mulheres. Entre seus feitos mais reportados, está o fato de a atleta não cantar o hino dos Estados Unidos em protesto con-

${ }^{7} \mathrm{O}$ futebol feminino já foi visto assim - o que diriam dessas imagens hoje? Disponível em: https:// dibradoras.blogosfera.uol. com.br/2019/05/22/o-futebol-feminino-ja-foi-visto-assim-o-que-diriam-dessas-imagens-ho$\mathrm{je} /$ ?cmpid=copiaecola. Acesso em 5 maio 2020. 
tra o presidente Donald Trump. A matéria com o título "A diversidade foi destaque nos estádios franceses na cobertura de TV na Copa" destaca a norte-americana. A revista traz também uma matéria como título "Virada de jogo" sobre a presença de mais jornalistas mulheres na cobertura do futebol.

Concluímos, assim, que, entre 2011 e 2019, as noticiabilidades caminharam para um tratamento ao futebol de mulheres com profissionalismo equivalente ao masculino, porém ainda longe de reservar espaços equânimes. Chegamos ao momento do tratamento a temas voltados à militância das futebolistas, às críticas ao sistema e à busca por equidade de gênero. Com a sexualização aparentemente superada, a luta agora é pelos anseios igualitários. Feito esse longo e detalhado passeio histórico pela década, com avaliação de três distintos períodos, nossa pesquisa propõe a existência de oito valores-notícia durante o período. No quadro abaixo, enumeramos e justificamos esses valores que, somados, contribuem para a mudança na noticiabilidade da Placar.

Figura 1 - Valores-notícia envolvendo futebol de mulheres na Placar entre 2011 e 2019

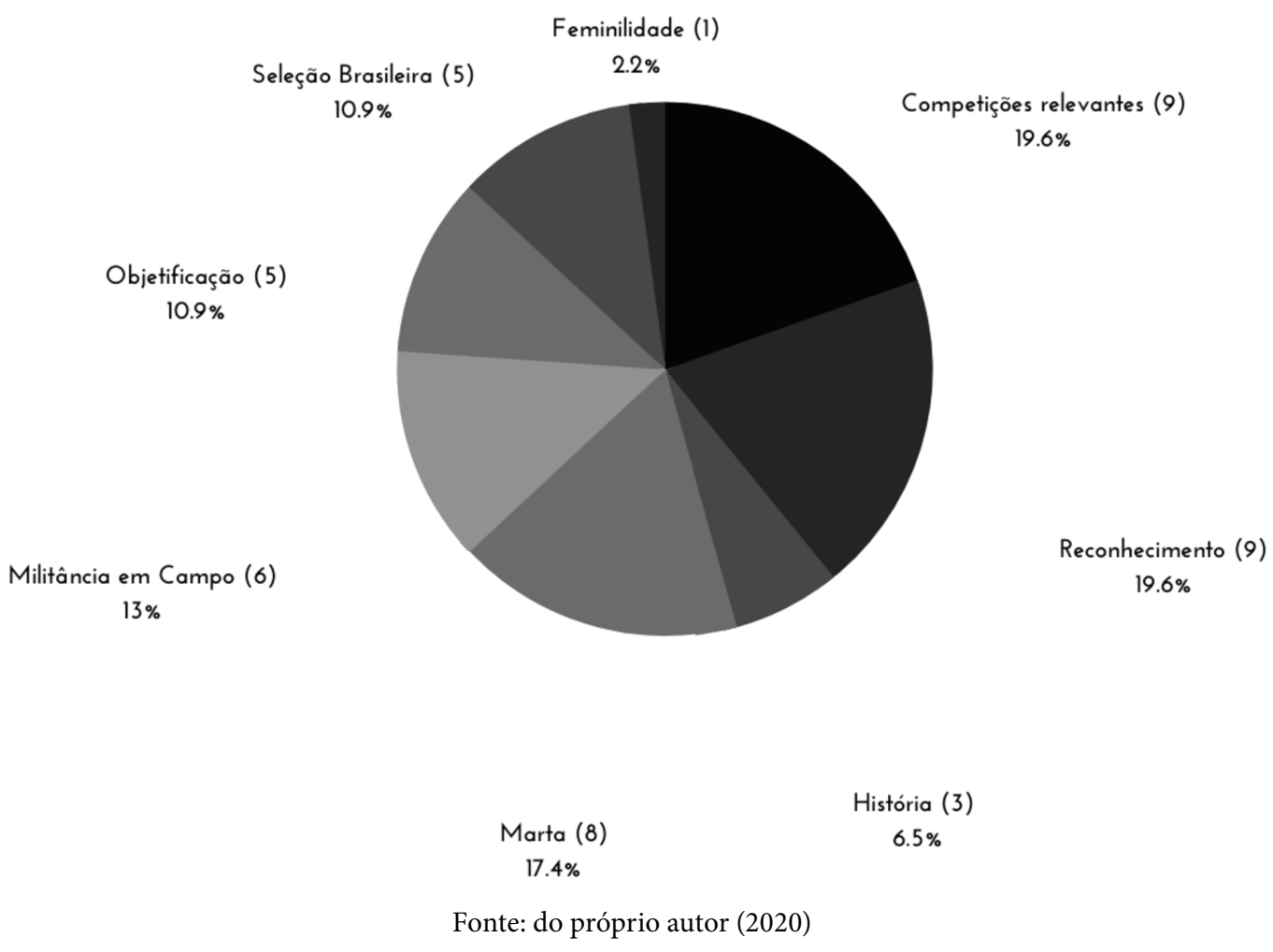

- Competições relevantes - Em geral, trazem informações curtas e básicas a exemplo de horários e locais de partidas de competições relevantes, como a Copa do Mundo e os Jogos Olímpicos; informações sobre o calendário, resultados, escalação das equipes. Normalmente, classificados no gênero nota, são conteúdos sem profundidade.

- Reconhecimento - Observamos esta noticiabilidade a partir da preocupação da revista em manter a temática presente na revista sempre com vieses que trazem o reconhecimento ao futebol de mulheres: seja a partir da cobrança à necessária profissionalização das esportistas; das reflexões sobre a explosão de interesse da própria mídia à modalidade; das notícias que envolvem recorrentes recordes de audiência; ou dos pedidos de desculpas. 
- Marta - A maior estrela do futebol de mulheres é em si um valor-notícia. Mais do que uma proeminência (SILVA, 2014), Marta chama para si o protagonismo de reportagens sobre clubes, condições de trabalho, desenvolvimento da modalidade e evolução da Seleção Brasileira.

- Militância em Campo - Nesta categoria, são destacadas notícias com vieses que vão além das quatro linhas do futebol. Os temas abarcados abrangem protestos de atletas como Megan Rapinoe (Estados Unidos) e Ada Hegerberg (Noruega), por igualdade de gênero e outras pautas políticas.

- Objetificação - Embora com conotação menos vulgar que em décadas passadas, a objetificação da mulher é evidenciada em jogo de palavras pejorativas (como "musas" ou trocadilhos com o termo "pelada"), ou seções de fotos que privilegiam ângulos mais invasivos ou notícias relacionadas à nudez de jogadoras.

- Seleção Brasileira - Diferentemente dos períodos anteriores, a Seleção Brasileira passa a ganhar maior atenção especialmente a partir dos Jogos Olímpicos de 2016. Com Marta em alta, mas também destaque para atletas como Cristiane e Formiga, a equipe nacional tem, ainda que pontualmente, espaço para reportagens especiais e informações sobre sua evolução nacional e internacional.

- História - Classificamos assim as notícias que se destacam pela preocupação em manter vivo o passado de luta e sofrimento pelo qual passaram as mulheres pioneiras no futebol brasileiro. É comum, nesta categoria, as lembranças sobre a proibição da modalidade entre 1941 e 1979; ganham espaço as curadorias em museus, acervos de fotografias e afins.

- Feminilidade - Embora com uma incidência muito menor, a década 2010 ainda encontrou espaço para notícias que permeiam o comportamento e a feminilidade.

\section{Considerações finais}

Entendemos a mídia como contribuinte para a construção social de uma realidade. Como parte da sociedade, também é, de certo modo, um catalisador dos anseios e câmbios sociais. Nesse sentido, compreendemos que a progressiva expansão do espaço na cobertura esportiva das mulheres na Placar e a mudança nos critérios de noticiabilidade da revista, potencializadas sobretudo a partir de 2016, possibilita observar as transformações pelas quais o periódico atravessou, em uma única década, passando de um produto que flertava com o passado de objetificação da mulher, para dar voz à modalidade, e dedicar, pela primeira vez na história, uma edição especial exclusiva ao futebol de mulheres

Ao observar, então, os valores-notícia nas décadas de 1990, 2000 e 2010, percebemos que tratamentos sexistas como os de "musas" e "gostosas" e termos como "salivava" ou "secava" foram ficando para trás graças a mudanças sociais pautadas, sobretudo, pela luta das mulheres por igualdade de gênero e outras pautas políticas. Uma cantada indesejada, uma frase que anos atrás era tida como "brincadeira de homem" passou a ser entendida como uma violência, uma agressão às mulheres.

A notícia sob um viés machista e de objetificação dos corpos foi abrindo espaço na revista para análises técnicas sobre o futebol de mulheres. Neste ponto, a chegada de Marta, com todos os seus títulos individuais e a revolução que ela 
provocou no cenário futebolístico, foi um fator crucial. Como pontuamos, o artigo é um fragmento de uma pesquisa maior sobre a Placar e a reflexão sobre as mudanças na noticiabilidade são algumas das muitas questões que trazem importantes olhares para o jornalismo, especialmente para o jornalismo esportivo.

\section{Referências}

ALSINA, M. A construção da Notícia. Petrópolis: Vozes, 2009.

BARRETO JANUÁRIO, S. Mulheres no campo: o ethos da torcedora pernambucana. São Paulo: Fontenele, 2019.

BARRETO JANUÁRIO, S.; VELOSO, A. Gênero, mídia e futebol: a cobertura midiática genderificada no Brasil. In: C. LIMA, C.; BRAINER, L.; BARRETO JANUÁRIO, S. (orgs.). Elas e o futebol. João Pessoa: Xeroca!, 2019.

BARRETO JANUÁRIO, S.; LIMA, C.; LEAL, D. Futebol de mulheres na agenda da grande mídia: uma análise temática da cobertura da Copa do Mundo de 2019. Observatório, v. 14, n. 4, 2020.

BARDIN, L. Análise de conteúdo. Lisboa: Edições 70, 1977.

BOURDIEU, P. A dominação masculina. Rio de Janeiro: Bertrand Brasil, 2012.

CORRÊA, R. Ricardo Corrêa: depoimento [set. 2019]. Entrevistadores: G. B. Mesquita e D. F. O. Leal. São Paulo, 2019.

COSTA, L. Maria-chuteiras x torcedoras "autênticas". Identidade feminina e futebol. XII ENCONTRO REGIONAL DE HISTÓRIA ANPUH-RJ. Usos do passado. Anais... Rio de Janeiro, 2006. p. 1-11.

COSTA, L. O futebol feminino nas décadas de 1940 a 1980. Revista do Arquivo Geral da Cidade do Rio de Janeiro. Rio de Janeiro, n. 13, p. 493-507, 2017.

DUARTE, J. Entrevista em Profundidade. In: DUARTE, J.; BARROS, A. Métodos e Técnicas de Pesquisa em Comunicação. 2. ed. São Paulo: Atlas, 2010.

FIGUEIREDO, C. D. \#martamelhorqueneymar: uma proposta de análise do uso de uma hashtag como indício de silenciamento da mídia tradicional. In: LIMA, C. A. R.; BRAINER, L.; JANUÁRIO, S. B. (orgs.). Elas e o futebol. João Pessoa: Xeroca!, 2019.

FONSECA JUNIOR, W. C. Análise de Conteúdo. In: Duarte, J.; Barros, A (Org). Métodos e Técnicas de pesquisa em comunicação. 2 ed. São Paulo: Atlas, 2006.

GOELLNER, S. V. Bela, maternal e feminina: imagens da mulher na "Revista Educação Physica”. Ijuí: Editora Unijuí, 2003.

GOELLNER, S. V. Mulher e esporte no Brasil: entre incentivos e interdições elas fazem a história. Pensar a prática. v.8, n.1, revisada. p. 65, 2005.

JORGE, T. de M. Mutação no jornalismo: como a notícia chega à internet. Brasília: Editora Universidade de Brasília, 2013. 
KFOURI, J. Juca Kfouri: depoimento [set. 2019]. Entrevistadores: G. B. Mesquita e D. F. O. Leal. São Paulo, 2019a.

KFOURI, J. A correta autocrítica da revista Placar. São Paulo: Portal UOL, 2019b. Disponível em: https://bit.ly/35a5hgN. Acesso em: 5 mai. 2020.

KNIJNIK, J. D.; SOUZA, J. S. S. Diferentes e desiguais: Relações de gênero na mídia esportiva brasileira; In. SIMÕES, A. C.; KNIJNIK, J. D. (orgs). O mundo psicossocial da mulher no esporte: comportamento, gênero, desempenho. São Paulo, Aleph, 2004, p. 191-212.

MESQUITA, G. Interfiro, logo existo: a audiência potente e as novas relações no jornalismo. (Tese de Doutorado). Programa de Pós-Graduação em Comunicação, Universidade Federal de Pernambuco, Recife, PE, Brasil, 2014.

MOURÃO, L.; MOREL, M. As narrativas sobre o futebol feminino: o discurso da mídia impressa em campo. Revista Brasileira de Ciências do Esporte, v. 26, n. 2, p. 73-86, 2005.

PLACAR. São Paulo: Editora Abril, edição 1106, ago., 1995.

PLACAR. São Paulo: Editora Abril, edição 1355, jun., 2011a.

PLACAR. São Paulo: Editora Abril, edição 1356, jul., 2011b.

PLACAR. São Paulo: Editora Abril, edição 1357, ago., 2011c.

PLACAR. São Paulo: Editora Abril, edição 1371, nov., 2012.

PLACAR. São Paulo: Editora Caras, edição 1408, nov., 2015.

PLACAR. São Paulo: Editora Caras, edição 1409, dez., 2015.

PLACAR. São Paulo: Editora Caras, edição 1418, ago., 2016.

PLACAR. São Paulo: Editora Abril, edição 1444, out., 2018.

PLACAR. São Paulo: Editora Abril, edição 1453, jul., 2019.

PLACAR. São Paulo: Editora Abril, edição 1457, nov., 2019.

RIBEIRO, A. Os donos do espetáculo: histórias da imprensa esportiva do Brasil. São Paulo: Terceiro Nome, 2007.

SALVINI, L.; MARCHI JÚNIOR, W. Registros do futebol feminino na Revista Placar: 30 anos de história. Motrivivência (Florianópolis); v. 28, n. 49, p. 99-113, dez. 2016.

SILVA, G. Para pensar critérios de noticiabilidade. In: SILVA, G.; SILVA, M. P.; FERNANDES, M. L. (orgs.). Critérios de noticiabilidade: problemas conceituais e aplicações. Florianópolis: Insular, 2014.

TRAQUINA, N. Teorias do Jornalismo, Volume II: A tribo jornalística - uma comunidade interpretativa transnacional, 2. ed. Florianópolis: Insular, 2005. 
TUCHMAN, G. La producción de la noticia. Estudo sobre la construcción de la realidad. Barcelona: Gili, 1983.

UNZELTE, C. Celso Unzelte: depoimento [set. 2019]. Entrevistadores: G. B. Mesquita e D. F. O. Leal. São Paulo, 2019a.

VEIGA DA SILVA, M. Masculino, o gênero do jornalismo: modos de produção das notícias. Florianópolis: Insular, 2014.

VEIGA DA SILVA, M. O Encontro entre a subjetividade e alteridade crítica das práticas jornalísticas: aproximações de pesquisa. Revista Observatório, Palmas, v. 4, n. 1, p. 398-417, jan.-mar. 2018.

WOLF, M. Teorias da comunicação. Lisboa: Editorial Presença, 2003. 